\title{
MUSEUM DENGAN PENDEKATAN KONSEP ARSITEKTUR TROPIS MODERN
}

\author{
Eva Gracia Anggina, Kelik Hendro Basuki
}

Indonesia memiliki keanekaragaman budaya, tradisi dan adat istiadat yang sudah turun termurun ada dan harus dijaga dan dilestarikan oleh penerus bangsa. Karya seni dan budaya yang ada di Indonesia itu telah melekat pada kehidupan sehari-hari masyarakat Indonesia. Seperti batik, songket, kain ulos, tenun sebagai kebutuhan sandang, ritual adat, makanan khas daerah, rumah-rumah adat, dan lainnya. Pentingnya keberadaan pengetahuan akan seni dan budaya Indonesia kepada masyarakat ini sangat diperlukan. Untuk itu diperlukan wadah untuk melestarikan, menjaga peninggalan tersebut yaitu bangunan Museum. Seiring berkembangnya zaman modern, masyarakat khususnya pada wilayah perkotaan mulai melupakan pentingnya peran dalam hal melestarikan budaya. Hal ini disebabkan karena sebagian besar masyarakat kurang berminat atau tertarik akan budaya yang terlihat kuno atau ketinggalan zaman. Dari sebanyak 328 museum di seluruh Indonesia, dalam setahun hanya mampu menarik 10 juta kunjungan. Angka tersebut relatif kecil dibandingkan dengan museum di negara lain dimana satu museum bisa menarik hingga 6 juta kunjungan. Museum sebagai hasil perancangan dimaksudkan untuk memberikan kenyamanan dan mendukung aktifitas manusia yang berada dalam bangunan tersebut. Kondisi ruangan yang baik adalah ruangan yang dapat memenuhi persyaratan kenyamanan yang meliputi kenyamanan terhadap suara, pencahayaan, kenyamanan. Oleh karena itu dalam pendekatan konsep yang diterapkan pada bangunan harus memperhatikan faktor iklim di indonesia, yaitu iklim tropis sehingga dapat tercipta lingkungan dan bangunan yang memberikan kenyamanan, kenikmatan, dan keselamatan terhadap pemakainya.

Kata kunci: Arsitektur, Iklim, Modern, Museum, Tropis

\begin{abstract}
Indonesia has a diversity of cultures, traditions and customs that have descended and have to be preserved and preserved by the nation's successors. Artwork and culture in Indonesia have been attached to the daily lives of Indonesian people. Such as batik, songket, ulos cloth, woven as clothing needs, traditional rituals, regional specialties, traditional houses, and others. The importance of the existence of knowledge of Indonesian arts and culture to the community is very much needed. For this reason, a container is needed to preserve and maintain the heritage of the Museum building. As the development of modern times, people especially in urban areas began to forget the importance of the role in terms of preserving culture. This is because most people are less interested or interested in cultures that look old or out of date. Of the 328 museums throughout Indonesia, in a year only able to attract 10 million visits. This figure is relatively small compared to museums in other countries where one museum can attract up to 6 million visits. The museum as a result of the design is intended to provide comfort and support human activities in the building. A good room condition is a room that can meet the comfort requirements which include the comfort of sound, lighting, comfort. Therefore in the concept approach applied to buildings must pay attention to climate factors in Indonesia, namely the tropical climate so as to create an environment and buildings that provide comfort, pleasure, and safety for the wearer.
\end{abstract}

Keywords: Architecture, Climate, Modern, Museum, Tropical

\section{PENDAHULUAN}

Indonesia merupakan negara yang memiliki keanekaragaman suku, budaya, karya seni yang itu ada dari zaman dahulu kala dan sekarang menjadi warisan nenek moyang yang harus dilestarikan. Keanekaragaman budaya inilah yang menjadi identitas dan kepribadian bangsa Indonesia. Karya seni dan budaya yang ada di Indonesia itu telah melekat pada kehidupan sehari-hari masyarakat Indonesia. Pentingnya keberadaan pengetahuan akan seni dan budaya Indonesia kepada masyarakat ini sangat diperlukan. Seiring berkembangnya zaman modern, masyarakat khususnya pada wilayah perkotaan mulai melupakan pentingnya peran dalam hal melestarikan budaya. Hal ini disebabkan karena sebagian besar masyarakat kurang berminat atau tertarik akan budaya yang terlihat kuno atau ketinggalan zaman. Dari sebanyak 328 museum di seluruh Indonesia, dalam setahun hanya mampu menarik 10 juta kunjungan. Angka tersebut relatif kecil dibandingkan dengan museum di negara lain dimana satu museum bisa menarik hingga 6 juta kunjungan. Kepala Subdirektorat Pengembangan dan Pemanfaatan Direktorat Pelestarian Cagar Budaya dan Permuseuman Kementerian Pendidikan Dasar Menengah dan Kebudayaan Dani Wigatna mengakui, hingga saat ini museum di Indonesia tidak begitu populer disebabkan kemasan dan pencitraan museum yang kurang menarik. Lalu bagaimana cara agar masyararakat kembali tertarik dan mengulas kembali makna budaya yang sebernarnya? Sebelum memulai semua hal tersebut, 
kita perlu memiliki wadah untuk menampung atau memamerkan koleksi karya seni yang ada. Itu sebabnya diperlukan sebuah Museum.

Pada proses perancangan arsitektur, disamping faktor manusia dan kebutuhan akan akan material bangunan, faktor iklim juga memiliki pengaruh yang besar terhadap suatu perancangan bangunan Keadaan iklim yang bemacam-macam di bumi ini menghadirkan gaya, langga,, sifat dan bentk arsitektur yang berbeda ragamnya. Di negara Indonesia yang iklimnya tropis lembab menghadirkan bangunan yang bersifat tertutup dan berorientasi ke dalam, dengan bukaan-bukaan kecil agar suhu udara luar tidak mengganggu kenyamanan ruang dalam. Sinar matahari, curah hujan, arah angin, dan suhu udara menentukan corak dan sifat arsitekturnya.

Faktor kenyamanan merupakan hal yang penting dalam merancang sebuah bangunan. Tetapi kenyataan selama ini umumnya bangunan belum mampu menghadirkan kenyamanan seperti yang diharapkan penggunanya, salah satunya disebabkan oleh ketidaknyamanan pada bangunan tersebut. Faktor iklim memiliki peranan dalam membentuk kenyamanan yang diharapkan. Tujuan mengetahui sejauh mana pengaruh iklim dalam perancangan arsitektur adalah dapat menghasilkan rancangan bangunan yang dapat memberikan kenyamanan. Dengan mengetahui dasar iklim yang baik maka inovasi dapat dilakukan dengan kaedah arsitektur yang menghasilkan karya arsitektur yang optimal.

\section{METODE PENELITIAN}

Penelitian ini dilakukan dengan metode analisis kualtatif dan dokumentasi.

a. Integrasi antara Museum dengan Pendekatan Arsitektur Tropis Modern

Museum pada dasarnya museum memiliki sifat bangunan yang cenderung tertutup untuk menjaga keawetan benda-benda koleksi di dalam museum tersebut. Sedangkan pada bangunan yang bersifat tropis modern lebih fokus kepada bangunan yang harus responsif terhadap iklim tropis. Bangunan harus dapat menyesuaikan iklim Indonesia yang memiliki curah hujan dan kelembaban tinggi, serta cahaya yang berlimpah.

\section{b. Orientasi Bangunan}

Orientasi bangunan pada umumnya dipengaruhi oleh beberapa faktor-faktor lingkungan yang ada di sekitar tapak. Faktor tersebut yaitu faktor pencahayaan matahari, curah hujan, dan arah angin.

c. Sistem Penghawaan pada Bangunan

Aliran udara terjadi karena adanya perbedaan temperatur antara udara di dalam dan di luar ruangan dan perbedaan tinggi antara lubang ventilasi.

\section{- Sistem Ventilasi Alamiah}

Hal ini diadaptasi dari sistem rumah panggung tradisional di Lampung yang sudah ada pada zaman dahulu. Konsep ini diterapkan ke dalam bangunan museum agar membuat ruangan lebih sejuk dan tidak terlalu menggunakan banyak energi.

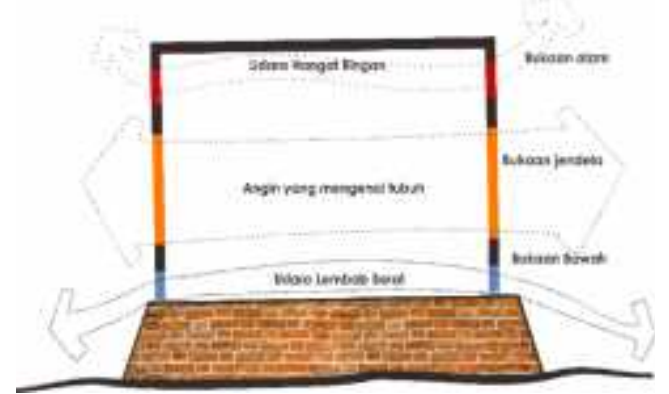

Gambar 1. Aliran Udara akibat perbedaan temperatur dalam Museum (Penulis,2019)

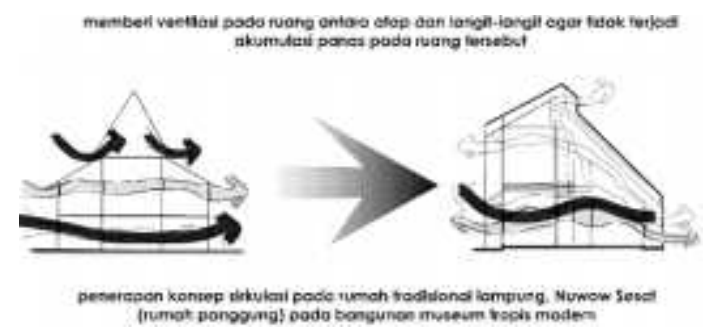

Gambar 2. Konsep Sirkulasi Udara terinspirasi oleh Rumah Tradisional Lampung (Penulis,2019)

\section{- $\quad$ Sistem Ventilasi Mekanis}

Penyaring udara dipasang di atas plafon di tiap-tiap ruangan, terhubung jalur aliran udara yang berpusat pada Heat Recovery Unit (MVHR) yang diletakan di ruangan di bawah atap atau loteng. Pada mesin tersebut udara yang terhisap terlebih dahulu di ekstraksi. Hasilnya udara bersih akan disalurkan kembali ke dalam ruangan, sedangkan udara yang tercemar akan dibuang keluar bangunan. Ventilasi dengan sistem ini sangat efektif dalam membersihkan udara yang terkontaminasi, bahkan menjebak debu dan serangga.

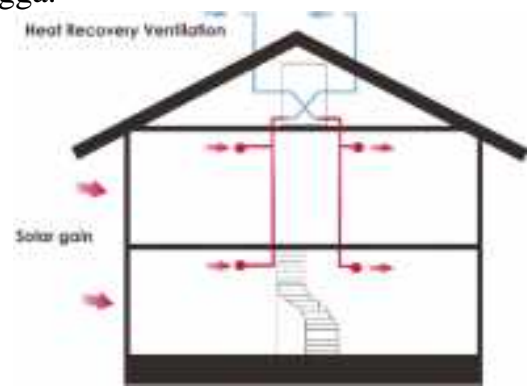

Gambar 3. Sistem ventilasi Mekanis pada Museum (Penulis, 2019)

\section{d. Sistem Pencahayaan Ruang}

Untuk mencegah sinar matahari yang langsung masuk ke dalam bangunan dapat dilakukan beberapa hal yaitu menempatkan ruang service di sisi jatuhnya radiasi matahari langsung (timur-barat). 


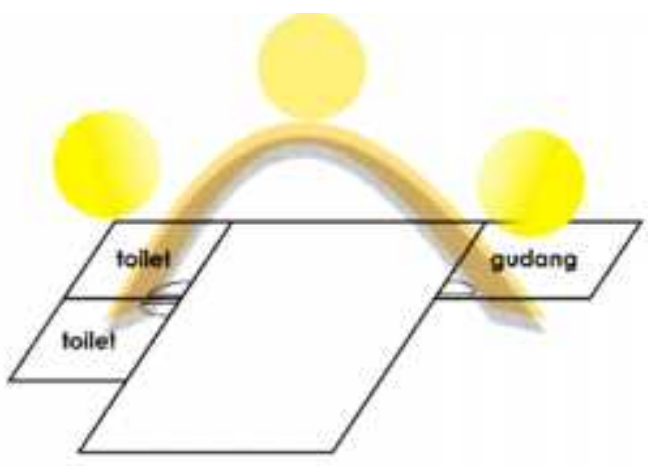

Gambar 4. Ruang Service pada sisi timur dan barat bangunan Museum (Penulis,2019)

Mengatur/mengarahkan pantulan cahaya matahari yang masuk ke dalam bangunan museum sehingga museum hanya terkena sinar matahari tidak langsung.

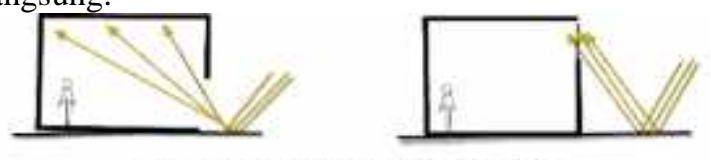

memantulkan cahaya melalul lantal/balkon

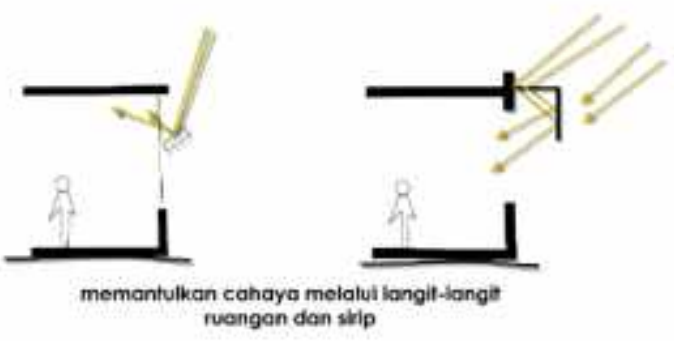

Gambar 5. Mengarahkan Pantulan Matahari pada Museum, Sumber (Penulis,2019)

Membuat ventilasi Louver (kisi-kisi) di beberapa ruangan untuk mengurangi sinar matahari terlalu banyak (memantulkan sinar matahari secara langsung menjadi tidak langsung) dan mendapat aliran udara secara alami ke dalam museum sehingga pengunjung tetap nyaman di dalam ruangan.

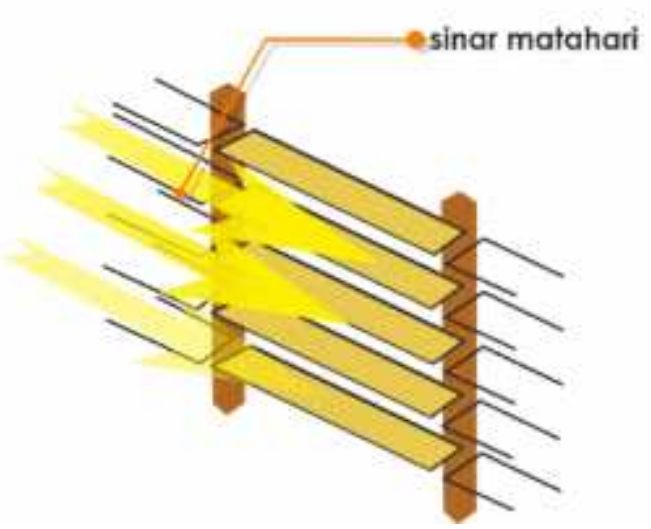

Gambar 6. Ventilasi untuk beberapa bagian Museum (Penulis, 2019)

\section{e. Pemanfaatan Air Hujan}

Sistem panen air hujan ini adalah mengumpulkan, menyaring, dan mengolah air hujan dan kemudian membuatnya siap untuk menyiram kebun dan halaman rumput, air penyiram di lavatory (flush), cadangan air untuk pemadam kebakaran (sprinkle), dan air pendingin ruangan. Air hujan dari atap, parkiran dikumpulkan dan dibawa melalui saringan sebelum berakhir di tangki penampung.

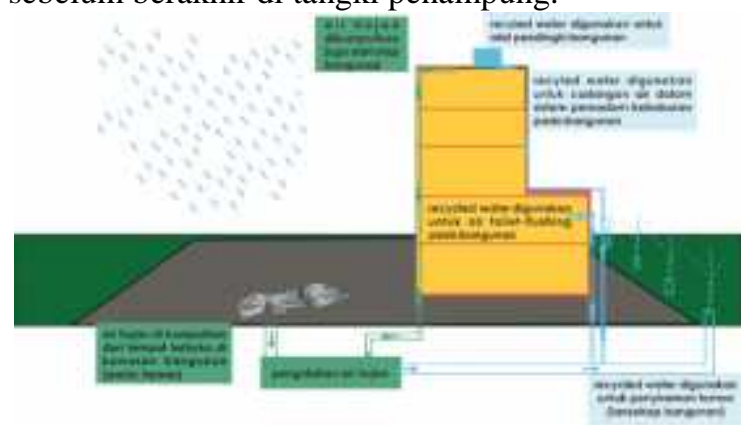

Gambar 7. Sistem Pemanfaatan Air Hujan pada Museum (Penulis,2019)

\section{f. Penggunaan bahan material bangunan}

Pada bangunan beriklim tropis menggunakan material yang sifatnya tidak menyimpan kalor dalam jumlah besar. Material alam dan pabrikasi merupakan bahan-bahan yang sering digunakan pada wilayah iklim tropis. Dasar pertimbangan dari pemilihan bahan banguan ini adalah daya tahan terhadap kondisi iklim setempat dan pengaruh terhadap tampilan bangunan.

\section{g. Pengaturan Vegetasi}

Membuat area perkerasan (pedestrian dan museum) terlindung dari radiasi matahari langsung dengan adanya penanaman pohon.

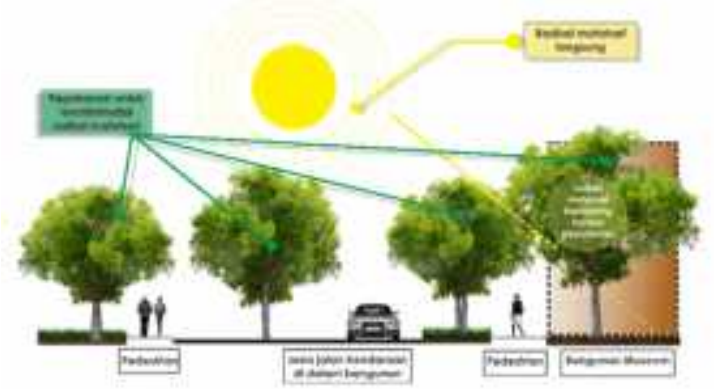

Gambar 8. Area Perkerasan Dilindungi Pohon, (Penulis, 2019)

Membuat Mini Garden Indoor atau taman kecil dan diberi void agar tanaman dapat mengurasi radiasi matahari dan memberikan oksigen yang cukup pada ruangan.

Menggunakan Secondary skin berupa vertical garden yang berfungsi menyejukkan dan tidak meneruskan radiasi matahari ke dalam bangunan serta menambah pemasukan oksigen ke dalam bangunan dan sekitarnya. Membuat amphi-theater tujuannya sebagai menambah visual hijau kawasan museum dan aktif dengan pertunjukan-pertunjukan 
seni. Serta kolam untuk menambah kesan sejuk yang airnya dikelola memanfaatkan air hujan yang dapat berfungsi sebagai pertunjukan seni juga.

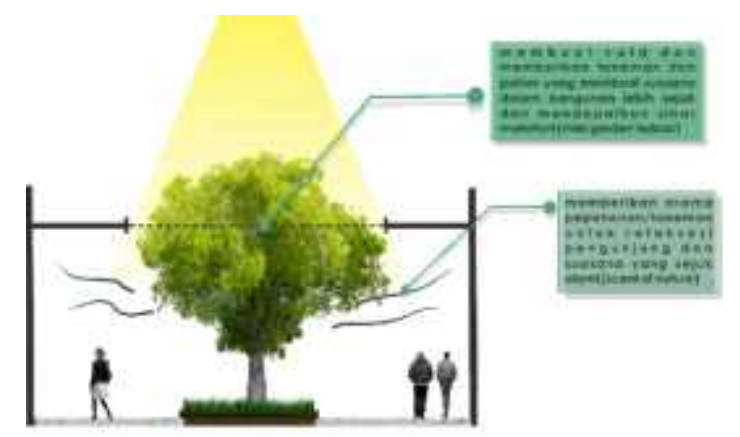

Gambar 9. Mini Garden Indoor (Penulis,2019)

\section{KESIMPULAN}

Berdasarkan hasil pengamatan penulis dengan menggunakan metode penelitian komparatif dan dokumentasi tentang penerapan pendekatan Arsitektur Tropis Modern terhadap Museum dapat disimpulkan bahwa permasalahan utama adalah bangunan yang belum menyesuaikan iklim di Indonesia. Penyelesaian dari permasalahan tersebut dapat diselesaikan dengan menerapkan aspek- aspek arsitektur tropis modern, yang menghasilkan pada bentuk dan wujud bangunan museum tersebut. Aspek dari Orientasi Bangunan, Sistem Penghawaan dengan sirkulasi yang terinspirasi dari Rumah Tradisional Lampung, menempatkan ruang service pada sisi timur barat bangunan, memanfaatkan air hujan yang digunakan untuk toilet Museum, mengatur vegetasi bangunan sehingga dapat mengurangi radiasi matahari, mengarahkan sinar matahari dengan pantulan cahaya sehingga bangunan mendapat cahaya matahari tidak langsung, menggunakan bahan material alam, dan membuat fasilitas penunjang seperti amphiteather agak menanbah kesan sejuk dan nyaman pada sekitar bangunan. Aspek-aspek tersebut sangatlah berkaitan dengan iklim dan cuaca dimana bangunan tersebut didirikan. Untuk itu hal-hal yang perlu diperhatikan adalah pada klimatologi bangunan tersebut, mulai dari pertimbangan panas, ventilasi dan angin, sinar matahari, serta curah hujan. Museum dengan pendekatan Konsep Arsitektur Modern bertujuan untuk mempertahankan nilai-nilai budaya dengan cara modern, nyaman dan sesuai dengan iklim tropis di Indonesia.

\section{DAFTAR PUSTAKA}

Form, Space, \& Order (D.K.Ching, 1999)

"Pengertian Museum Menurut Para Ahli", www.aanwijzing.com/2018/05/pengertianmuseum-menurut-para-ahli-dan-pentingnyamempelajari-museum, diakses pada 11 Januari 2019.

\author{
"Pengertian Arsitektur Tropis Modern" , \\ www.dekoruma.com/artikel/71645/apa-itu- \\ arsitektur-tropis, diakses pada 18 Januari \\ 2019.
}

